\title{
Parents Attitude toward Education among Muslim
}

\author{
Dr. Huma Hilal ${ }^{1 *}$
}

\section{ABSTRACT}

Education is one of the major instruments of social change and it is the force, which brings changes in the traditional outlook of the people, and it develops insight for judging things in their context. It is assume that more the percentage of educated people more will be the rate of development. As all we say that Education of a girl is like educating a family while educating a boy is merely educating a person. The importance of female education in a society and its spreading to all section of the life is well appreciated and documented to solve existing and emerging problems of the society. There is ample evidence that children from better educated parents more often go to school and tend to drop out less (UNESCO, 2010). Parents who have reached a certain educational level might want their children to achieve at least that level (Breen \& Goldthorpe, 1997). For educational enrolment of girls, education of the mother might be especially important (Emerson \& Portela Souza, 2007; Shu, 2004; Kambhampati \& Pal, 2001; Fuller, Singer and Keiley, 1995). Mothers who have succeeded in completing a certain level of education have experienced its value and know that it is within the reach of girls to complete that level.

The present research was aimed at assessing attitude of parents toward education among Muslim. Sample consists of 100; in which 50 male respondents and 50 female respondents were participated in the present research. Parents' attitude was measured through Questionnaire consisting 23 items which is developed by Patnaik \& Samal (2012). The respondents were required to indicate their agreement or disagreement with each of the statements about children's education in a four-point Likert type scale, where 1 denotes strong disagreement and 4 denotes strong agreement. Mean scores were calculated separately for male and female respondents and high socio economic status and low socio economic status samples. The t test was used to examine the significance of difference between male and female respondents as well as high socio economic status and low socio economic status with regard to their attitude towards children's education. The findings showed that the overall attitude of the respondents was moderately favourable and positive towards education of their children. This result was discussed in the light of existing findings and with other demographic variable i.e. education of the parents, income of the parents and number of children.

Keywords: Parents Attitude, Education, Muslim

\footnotetext{
${ }^{1}$ Post Doctoral Fellow (UGC), Department of Psychology, Aligarh Muslim University, Aligarh, UP, India *Responding Author

(C) 2016, H Hilal; licensee IJIP. This is an Open Access Research distributed under the terms of the Creative Commons Attribution License (http://creativecommons.org/licenses/by/2.0), which permits unrestricted use, distribution, and reproduction in any Medium, provided the original work is properly cited.
} 


\section{Parents Attitude toward Education among Muslim}

There is a strong demand and genuine desire of an educational program that all the study should make adjustment to modern concept and application to common need of life. Progress in any field requires a clear understanding of its elementary concept. India is a developing country and is facing many problems in education system including of higher rate of illiteracy of its population especially the female population. This problem is rooting various other problems also. During the time of Independence, India's education system was characterized by regional, gender, caste and structural imbalances. Only 14 percent of the population was literate and only one out of three children were enrolled in primary schools (Government of India, Ministry of I \& B, (1996), India 1995, P.79).

Education is one of the major instruments of social change and it is the force, which brings changes in the traditional outlook of the people, and it develops insight for judging things in their context. It is assume that more the percentage of educated people more will be the rate of development. As all we say that Education of a girl is like educating a family while educating a boy is merely educating a person. The importance of female education in a society and its spreading to all section of the life is well appreciated and documented to solve existing and emerging problems of the society. There is ample evidence that children from better educated parents more often go to school and tend to drop out less (UNESCO, 2010). Parents who have reached a certain educational level might want their children to achieve at least that level (Breen \& Goldthorpe, 1997). For educational enrolment of girls, education of the mother might be especially important (Emerson \& Portela Souza, 2007; Shu, 2004; Kambhampati \& Pal, 2001; Fuller, Singer and Keiley, 1995). Mothers who have succeeded in completing a certain level of education have experienced its value and know that it is within the reach of girls to complete that level.

Education as a means of advancement of capacity well-being and opportunity is uncontested, and more so among communities on the periphery. Marked improvements in access and to some extent in quality of primary education in tribal areas have occurred, and stem from government and non-government initiatives. However, the number of out-of-school children continues to be several millions, mainly due to a lack of interest and parental motivation, inability to understand the medium of instruction (i.e. state language), teacher absenteeism and attitude, opportunity cost of time spent in school (particularly for girls), large seasonal migration etc. Low literacy rates in tribal communities continue to indicate a need for overarching support that tackles issues from health.

Sen (1992) in his study found that the cultural factors may play an intermediate role. They influence the choices made by individuals, through their own attitudes, and those of the people in their close environment. With respect to culture, India is part of what Caldwell (1982) has called the belt of classical patriarchy that stretches from North Africa to China and includes both Muslim, Hindu and Confucian cultures. His result indicated that the cultural factors show that

(C) The International Journal of Indian Psychology, ISSN 2348-5396 (e) | ISSN: 2349-3429 (p) | 200 


\section{Parents Attitude toward Education among Muslim}

belonging to a disadvantaged caste or tribe is negatively associated with schooling. Girls belonging to a scheduled caste are less in school in rural areas and girls belonging to a scheduled tribe are less in school in urban areas. The odds of being in school are also significantly reduced for children whose mothers had their first child at a young age and for children whose mothers have a preference for boys over girls. The percentage of women compared to men in the age group 20-59 is positively related to the odds of being in school in rural areas, thus his result 16 indicated that in districts with less "missing women" the chances of children being in school are higher.

Huisman, Rani, and Smits, (2009) studied the role of socio-economic and cultural factors, and of characteristics of the educational infrastructure on primary school enrolment, The sample constituted 70,000 children living in 439 districts of 26 states of India. The results indicated that most of the variation in educational enrolment (around 70\%) is explained by factors at the household level, of which socio-economic factors are most important. And the result also indicated that, in the cities schooling decisions are hardly influenced by supply-side factors. In rural areas, however, these factors do play an important role. If there are fewer schools or teachers, or if the local culture is more patriarchal, rural children (in particular girls) participate substantially less. The major finding of this respect was that in rural areas inequalities between socio-economic status groups are lower if more schools and teachers are available. It has been found that three major determinants of educational enrolment: socio-economic status, educational infrastructure, and culture have an impact on primary school participation in India (Evangelista de Carvalho Filho, (2008); Mingat, (2007); Shavit and Blossfeld, (1993); Jencks, (1972); Coleman, James, Campbell, Hobson, McPartland, Mood, Weinfeld, and York (1966). Socio-economic indices like the characteristics of households, parental income, wealth, education and occupation, have long been known to be major determinants of educational enrolment and achievement in both developing and developed countries.

TNS Social research (September 2003-June 2004) stated that parents' attitudes towards education were generally very positive. The majority (97\%) agreed that a good education would help their child to get ahead in life. While 93\% thought the qualifications were important to their child's future, $90 \%$ also agreed that children learn important life skills at school. Three quarters of parents (76\%) agreed that their child's school is good at communicating with them and the majority (86\%) agreed that their child's teachers do a great job. Just over a fifth (22\%) felt that their child's school tended to be too interested in bright children at the expense of the others, although only $7 \%$ thought that the school takes too much interest in their child's home life. Just under a fifth of parents/career (18\%) thought that most of the things their child learns at school are not relevant to real life. A small proportion (14\%) of parents saw it as acceptable that if their child did not want to study now, s/he could study when s/he was older. Their study was based on to identify whether there were any differences in parents' attitudes towards attendance between the general population and a group of parents whose children were currently not attending

(C) The International Journal of Indian Psychology, ISSN 2348-5396 (e)| ISSN: 2349-3429 (p) | 201 


\section{Parents Attitude toward Education among Muslim}

school. This research has not identified any differences in the attitudes of parents in the general population.

An attitude is "a relatively enduring organization of beliefs, feelings, and behavioral tendencies towards socially significant objects, groups, events or symbols" (Hogg \& Vaughan 2005, p. 150). Attitude is the feeling or mental disposition of an individual which influences the human behavior. Attitude is a vital ingredient for the success or failure of children in their optimum development. Attitudes structure can be described in terms of three components.

$>\quad$ Affective component: this involves a person's feelings / emotions about the attitude object. For example: "I am scared of spiders".

$>$ Behavioral (or conative) component: the way the attitude we have influences how we act or behave. For example: "I will avoid spiders and scream if I see one”.

$>$ Cognitive component: this involves a person's belief / knowledge about an attitude object. For example: "I believe spiders are dangerous".

This model is known as the ABC model of attitudes. The three components are usually linked. However, there is evidence that the cognitive and affective components of behavior do not always match with behavior. This is shown in a study by LaPiere (1934). The attitude of parents can have a profound effect on the social and educational integration of children. It makes a great difference to these children whether the attitude and actions of parents reflect considerations for their real needs or are merely prompted by pity or monetary limitations. It is a determinant of behavior. Our behavior depends upon our attitude, which is holding positive and negative belief regarding any concept. Behavior is formed by attitude. All these three components are affects the parental attitude towards their children's education. If all the three components are positive then the individual's action, belief and feeling towards education should be positive. The belief component of attitude affects the action component. If a person perceives something favorable then his/her action must be favorable. In this situation if the parent's belief towards education is favorable then it affects their action component, and it must be positive and favorable. Attitudes can serve functions for the individual. Katz (1960) outlines the functional areas:

- Knowledge- Attitudes provide meaning (knowledge) for life. The knowledge function refers to our need for a world which is consistent and relatively stable. This allows us to predict what is likely to happen, and so gives us a sense of control. Attitudes can help us organize and structure our experience. Knowing a person's attitude helps us predict their behavior.

- Adaptive- If a person holds and/or expresses socially acceptable attitudes, other people will reward them with approval and social acceptance. Attitudes then, are to do with being a part of a social group and the adaptive functions helps us fit in with a social group. People seek out others who share their attitudes, and develop similar attitudes to those they like.

(C) The International Journal of Indian Psychology, ISSN 2348-5396 (e) | ISSN: 2349-3429 (p) | 202 
- The ego-defensive function- refers to holding attitudes that protect our self-esteem or that justify actions that make us feel guilty. Positive attitudes towards ourselves, for example, have a protective function (i.e. an ego-defensive role) in helping us reserve our self-image.

\section{Research Objectives}

Following are the main research objective of the present research:

1. To examine the attitudes of parents towards education of their children.

2. To examine the difference between the attitude of father and mother toward education of their children.

3. To examine the difference between the attitudes of parents having high socio economic status and having low socio economic status.

4. To examine the difference between highly educated attitude of the parents and low educated attitude of parents.

\section{METHODOLOGY}

Design of the Study

A multiple randomized group design was used in the present research. The sample of the study was divided into four groups namely father having high socio economic status $(\mathrm{N}=25)$, mother having high socio economic status $(\mathrm{N}=25)$, and father having low socio economic status $(\mathrm{N}=25)$, mother having low socio economic status $(\mathrm{N}=25)$.

\section{Sample}

Socio-Economic Status Scale was administered on 180 subjects belong to Muslim family of Aligarh (U.P) India. On the basis of their score on SESS 100 parents were selected; in which 50 male respondents (father) and 50 female respondents (mother). More specifically 25 male respondent having high socio economic status and 25 male respondent having low socio economic status and 25 female respondent having high socio economic status and 25 female having low socio economic status were participated in the present research. Those respondents who obtained 61 and above score were consider as high-economic status and those who obtained 31 to 60 score were consider as low socio-economic status. Further the parents categorized as highly educated parents (Graduate and above) and low educated parents (intermediate and below).

\section{Instruments}

\section{Socio-Economic Status Scale (SESS)}

Socio-Economic Status Scale (SESS) developed by Aggarwal, Bhasin, Sharma, Chhabra, Aggarwal, and Rajoura (2005) was employed to determine the Socio-Economic Status of the subjects. The scale consisted of 22 items. Suitable weight age was given to each item and scoring for each item was based on a scale ranging from 3 to 9.Question 18 i.e. regarding the presence of non milch cattle or pets in the family was scaled on a 3 point scale and question 12 regarding 


\section{Parents Attitude toward Education among Muslim}

living in the type of a house was scaled on a 9 point scale. The maximum aggregate score was 100. Based on the final score, the socio-economic states of the family is divided into six socioeconomic categories, namely Upper high (combined score of more than 76), High (61-75), Upper Middle (46-60), Lower Middle (31-45), Poor (16-30) and Very Poor (combined score less than 15). The study was carried out in five different strata namely the urban, rural, resettlement colony, slum/ jhuggis and amongst those who were mobile and had no fixed living respectively. Data was collected by second semester undergraduate medical students. The reliability and validity of this scale was found to be 0.77 and 0.533 respectively.

\section{Attitude toward Education Scale}

Attitude toward Education Questionnaire consisted 23 items which was developed by Patnaik \& Samal (2012). The respondents were required to indicate their agreement or disagreement with each of the statements about children's education in a four-point Likert type scale, where 1 denotes strong disagreement and 4 denotes strong agreement. These 23 statements in the questionnaire were finalized after a thorough review of literature and all the statements reflected the value of schooling and education for a child's future. Equal numbers of positive and negative statements were included in the questionnaire. A pilot survey of questionnaire was conducted. At the initial stage of field work each houses were numbered and rapport was established with the respondents for generating honest responses. Household schedule information and biographical data was collected prior to the collection of data. Respondents were included from each of the household. Assessment was done individually in odia language. After the respondents completed the rating of statements, data was also collected about the future plans for their child education and other miscellaneous matters through open ended questions. After data collection, the ratings of respondents were scored keeping in mind the negative and positive statements in the questionnaire (Reverse scoring was done for negative statements). Cronbach's Alpha was found to be 0.718 .

\section{Procedure}

First of all rapport with the subject was made, and then Attitude scale (2012) and SocioEconomic Status Scale (2005) were used to assess the attitude and socio economic status of parents. These Scales were administered either individually or in a small group of subjects.

\section{Data Analysis}

The data were analyzed by t-test in which I compared father and mother attitude toward education of their children on overall score and attitudes of parents having high socio economic status and having low socio economic status. Further I compare highly educated attitude of the parents and low educated attitude of parents. 
RESULT AND DISCUSSION

Table I: Showing mean score of two groups, SD and t-value.

\begin{tabular}{|l|l|l|l|}
\hline Groups & Mean & SD & t-value \\
\hline Father & 59.18 & 3.52 & .807 \\
\hline Mother & 60.18 & 8.01 & \\
\hline
\end{tabular}

Table II: Showing mean score of two groups, SD and t-value.

\begin{tabular}{|l|l|l|l|}
\hline Groups & Mean & SD & t-value \\
\hline High SES Respondent & 62.10 & 2.29 .19 & $4.23^{*}$ \\
\hline Low SES Respondent & 57.26 & 7.74 & \\
\hline
\end{tabular}

Table III: Showing mean score of two groups, SD and t-value.

\begin{tabular}{|l|l|l|l|l|}
\hline Groups & N & Mean & SD & t-value \\
\hline Highly Educated Parents & 18 & 50.33 & 8.83 & $10.03^{* *}$ \\
\hline Low Educated Parents & 82 & 61.73 & 2.58 & \\
\hline
\end{tabular}

Results of the present research indicated that the mean score of the total sample was 59.68 which is not quite high. When I see the maximum score for the scale is 92 and minimum is 23 . The mean score indicated that attitude of the respondents was moderately favourable and positive towards education of their children. Results supported the earlier studies (Evangelista de Carvalho Filho, 2008; Mingat, 2007; Shavit \& Blossfeld, 1993; Jencks, 1972; Coleman, James, Campbell, Hobson, McPartland, Mood, Weinfeld, and York (1966) that low socio-economic status can adversely affect the attitude towards schooling and education. However, the moderately favourable and not-so-unfavourable attitude found in the study throws light on the fact that growing awareness regarding literacy and education around the country has significantly affected all sections of the society including the tribal population. The value attached to schooling and education of children has substantially improved than earlier times when lack of literacy and education was the norm and sending children to school in a tribal community was an exception. Engagement of children in traditional occupation was considered to be more lucrative by the parents as it contributed to the family income; whereas education was considered as wastage of time and money since its outcome was uncertain and unimportant.

As shown in Table I the mean score of father is 59.18 and the mean score of mother is 60.18. The t-value is 0.807 which is insignificant at 0.05 level, indicating that father and mother did not differ in attitude toward education of their children. It means that they have the almost same attitude toward education of their children. Our finding also supported by Patnaik \& Samal (2012) found that the attitude of the male and female respondents regarding schooling and education of their children did not differ significantly.

(C) The International Journal of Indian Psychology, ISSN 2348-5396 (e) | ISSN: 2349-3429 (p) | 205 


\section{Parents Attitude toward Education among Muslim}

As shown in Table II the mean score of parents having high socio economic status is 62.10 and the mean score of parents having low socio economic status is 57.26 . The t-value is 4.23 which is significant at 0.05 level, indicating that high socio economic status and low socio economic status respondent differ in attitude toward education of their children. It means that parents having high socio economic status have more positive attitude toward education of their children as compared to parents having low socio economic status.

Both in developed and developing countries, children from families with more socio-economic resources are more often enrolled in school. For wealthier families, the direct costs associated with education, such as fees, books and uniforms are less likely to be an obstacle. Opportunity costs of children not being able to help at home, at the family farm or by earning additional income through child labour, are also less important to them (Evangelista de Carvalho Filho, 2008; Basu, 1999).

As shown in Table III the mean score of highly educated parents is 61.73 and the mean score of low educated parents is 50.33. The t-value is 10.03 which is significant at 0.05 level, showing that highly educated parents and low educated parents differ in attitude toward education of their children. It means that educated parents want more to educate their children as comparison to low educated parents because they understand the value of education. Our finding is consonant with the finding obtained by so many researchers. There is ample evidence that children from better educated parents more often go to school and tend to drop out less (UNESCO, 2010). Parents who have reached a certain educational level might want their children to achieve at least that level (Breen \& Goldthorpe, 1997). For educational enrolment of girls, education of the mother might be especially important (Emerson \& Portela Souza, 2007; Shu, 2004; Kambhampati \& Pal, 2001; Fuller, Singer and Keiley, 1995). Mothers who have succeeded in completing a certain level of education have experienced its value and know that it is within the reach of girls to complete that level. Therefore, we expect them to use the power and insights derived from their higher education to make sure that their daughters are educated too (Smits \& Gunduz-Hogor, 2006).

Family involvement is the strongest predictor of child educational outcomes. This dimension associated significantly with children's motivation to learn, attention, task persistence, receptive vocabulary skills, and low conduct problems. Family involvement in education has been identified as a beneficial factor in young children's learning (National Research Council [NRC], 2001; U.S. Department of Education, 2000). It is, therefore, a key component of national educational policies and early childhood programs. Much of the research on parent involvement, as it relates to children's outcomes, has emphasized the relationship between specific parent involvement behaviors and children's achievement. Parental involvement at school (e.g., with school activities, direct communication with teachers and administrators) is associated with greater achievement in mathematics and reading (Griffith, 1996; Reynolds, 1992; Sui-Chu \&

(C) The International Journal of Indian Psychology, ISSN 2348-5396 (e) | ISSN: 2349-3429 (p) | 206 


\section{Parents Attitude toward Education among Muslim}

Willms, 1996). Higher levels of parent involvement in their children's educational experiences at home (e.g., supervision and monitoring, daily conversations about school) have been associated with children's higher achievement scores in reading and writing, as well as higher report card grades (Epstein, 1991; Griffith, 1996; Sui-Chu \& Willms, 1996; Keith, Keith, Quirk, Sperduto, Santillo, \& Killings, 1998). Other research has shown that parental beliefs and expectations about their children's learning are strongly related to children's beliefs about their own competencies, as well as their achievement (Galper, Wigfield, \& Seefeldt, 1997). Parents who evidenced high levels of school contact (volunteering in the classroom, participating in educational workshops, attending Policy Council meetings) had children who demonstrated greater social competency than children of parents with lower levels of school contact (Parker, Piotrkowski, Kessler-Sklar, Baker, Peay, \& Clark, 1997).

\section{Acknowledgments}

The author appreciates all those who participated in the study and helped to facilitate the research process.

\section{Conflict of Interests}

The author declared no conflict of interests.

\section{REFERENCES}

Aggarwal, O.P., Bhasin, S.K., Sharma, A.K., Chhabra, P., Aggarwal, K., \& Rajoura, O.P (2005). A New Instrument (Scale) for Measuring the Socioeconomic Status of a Family: Preliminary Study. Indian Journal of Community Medicine, 30 (4),

Basu, K. (1999). Child labor, consequence, and cure, with remarks on international labor standards. Journal of Economic Literature, 3, 1083-1119.

Breen, R., \& Goldthorpe, J. H. (1997). Explaining Educational Differentials: Towards a Formal Rational Action Theory. Rationality and Society, 9(3), 275-305.

Caldwell, J. (1982). Theory of fertility decline. London: Academic Press.

Coleman, James S., Campbell, E.Q., Hobson, C.J., McPartland, J., Mood, A.M., Weinfeld, F.D. \& York, R.L. (1966). Equality of educational opportunity. Washington, D.C.: U.S. Government Printing Office. Central Statistical Organisation (CSO), (1998).

Emerson, P.M. \& Portela Souza, A. (2007). Child Labor, School Attendance, and Intrahousehold Gender Bias in Brazil. The World Bank Economic Review, 21(2), 301-316.

Epstein, J. L. (1991). Effects on student achievement of teachers' practices of parent involvement. In S. B. Silvern (Ed.), Advances in reading/language research: Vol. 5. Literacy through family, community and school interaction (pp. 261-276). Greenwich, CT: JAI Press.

Evangelista de Carvalho Filho, Irineu (2008). Household income as a determinant of child labor and school enrollment in Brazil. IMF Working Paper, WP/08/241. 
Fuller, B., Singer, J. D., \& Keiley. (1995). 'Why Do Daughters Leave School in Southern Africa?' Social Forces, 74, 657-680.

Galper, A., Wigfield, A., \& Seefeldt, C. (1997). Head Start parents' beliefs about their children's abilities, task values, and performances on different activities. Child Development. 68, 897-907.

Government of India, Ministry of I \& B, (1996), India 1995, P.79

Griffith, J. (1996). Relation of parental involvement, empowerment, and school traits to student academic performance. Journal of Educational Research, 90, 33-41.

Huisman J. \& Smits, J. (2009). Keeping children in school: Household and district-level determinants of school dropout in 363 districts of 30 developing countries. NICE Working Paper 09-105, Nijmegen: Radboud University.

Huisman J. and Smits, J. (2009). 'Keeping children in school: Household and district-level determinants of school dropout in 363 districts of 30 developing countries.' NICE Working Paper 09-105, Nijmegen: Radboud University.

Jencks, C (1972). Inequality: A Reassessment of the Effect of Family and Schooling in America. New York: Basic Books.

Kambhampati, U \& Pal, S. (2001). Role of Parental Literacy in Explaining Gender Difference: Evidence from Child Schooling in India. European Journal of Development Research, 13(2), 97-119.

Katz, D. (1960). Public opinion quarterly, 24, 163 - 204.

Keith, T. Z., Keith, P. B., Quirk, K. J., Sperduto, J., Santillo, S., \& Killings, S. (1998). Longitudinal effects of parent involvement on high school grades: Similarities and differences across gender and ethnic groups. Journal of School Psychology 36, 335-363.

LaPiere, R. T. (1934). Attitudes vs. actions. Social Forces, 13, 230-237.

Mingat, Alain (2007). Social Disparities in Education in Sub-Saharan African Countries. In Teese, R., Lamb, S. and Duru-Bellat, M. (eds.) International Studies in Educational Inequality, Theory and Policy, Vol. 1. Dordrecht: Springer.

Parker, F. L., Piotrkowski, C. S., Kessler-Sklar, S., Baker, A. J., Peay, L., \& Clark, B. (1997). Parent involvement in Head Start (Executive summary). New York: National Council of Jewish Women Center for the Child.

Patnaik, B. \& Samal, R. (2012). Parents' attitude towards school and education of children. Project report submitted to Department of Humanities and Social Sciences for the partial fulfillment of the requirement in Master's Degree in Development Studies. http://ethesis.nitrkl.ac.in/3233/1/Final.pdf

Reynolds, A. J. (1992). Comparing measures of parental involvement and their effects on academic achievement. Early Childhood Research Quarterly, 7, 441- 462.

Sen, A. (1992) 'Missing women.’ British Medical Journal, 304, 586-587.

Shavit, Y \& Blossfeld, Hans-Peter (1993). Persistent Inequality: Changing Educational Attainment in Thirteen Countries. Boulder: West view Press.

Shu, Xiaoling (2004). 'Education and Gender Egalitarianism: The Case of China.' Sociology of Education, 77: 311-336. 
Smits, J., \& Gündüz-Ho_gör, A. (2006). Effects of family background characteristics on educational participation in Turkey. International Journal of Educational Development, 26, 545-560.

Sui-Chu, E. H., \& Willms, J. D. (1996). Effects of parental involvement on eighth-grade achievement. Sociology of Education, 69, 126-141.

UNESCO, Education For All Global Monitoring Report 2010: Reaching the Marginalized. Paris: UNESCO (2010).

How to cite this article: H Hilal (2016), Parents Attitude toward Education among Muslim, International Journal of Indian Psychology, Volume 3, Issue 4, No. 65, ISSN 2348-5396 (e), ISSN: 2349-3429 (p), DIP:18.01.153/20160304, ISBN: 978-1-365-34680-4

(c) The International Journal of Indian Psychology, ISSN 2348-5396 (e)| ISSN: 2349-3429 (p) | 209 